\title{
Internet resources for chemistry
}

\author{
By Francie Bauer
}

\section{A compendium of information from quick facts to 3-D images}

$\mathbf{L}$ ike all information available over the Internet, chemical information has proliferated rapidly. For scientists as well as reference librarians, getting accurate information quickly is critical. Much progress has been made in collecting, building, organizing, and verifying chemical information. Since the Internet is an ongoing, amorphous process, links may change or be temporarily unavailable, but there are many sites to choose from now. Yet it is still a "buyer beware" market. There is much free information and many sites will link directly to other sites with still more information, but there is no guarantee that the records or information obtained has been checked, verified, juried, or refereed by peers in the scientific community, which is an important consideration for providers of scientific information.

Chemical information is of potential use and interest across a wide variety of academic disciplines as well as in business, corporate, pharmaceutical, and industrial companies. Researchers in animal science, molecular biology, chemical engineering, materials science, plant and soil science, botany, biology, zoology, veterinary science, pharmacology, and medicine can all have need of chemical information. With the current interest and emphasis on protecting the environment, many businesses and industries will also need current, accurate chemical information.

There are excellent compilations available but the changing nature of the Internet makes it hard to be comprehensive. Care has been taken to mention sites in which an effort has been made to organize, check, and verify data as well as offer it free to the browser. The user should still check for disclaimers when using the information without further verification.

\section{Best sites/good places to start}

For a general overview of what is available, here are several sites that have well-organized directories and provide direct links to resources all over the world.

- The World-Wide Web Virtual Library: Chemistry. This has one of the best, most comprehensive, easy-to-use directories available. The contents page is arranged by type of site from academic institutions and nonprofit organizations to commercial ones. It also indexes gopher servers and usenet groups and links to other sites for Chemistry Resources. Access: http:/ /www.chem.ucla edu/chempointers.html.

- Chemistry on the Internet: The Best of the Web 1995. Originally presented at an American Chemical Society symposium, this is a selected list of the authors' top picks for the "best world collections of chemistry and chemistry-related resources." It also lists who compiled the resources. Visitors can vote for the 1996 awards. Besides the collection of general pointers, there are links to Chemical Internet Standards, Visual and Teaching Resources, Electronic Journals, and Conferences. For serious researchers there is also a very useful collection of specialized "value-added" lists of processed information. Access: http://argon. ch.ic.ac.uk/infobahn/boc.html.

\section{"Value-added," subject-oriented sites}

- SCOP: Structural Classification of Proteins. Quality descriptions of the structural and 
evolutionary relationships of all known protein structures. Free to academic searchers; commercial users must subscribe. Access: hittp: /scop.mrc-lmb.cam.ac.uk/scop/.

- Expasy Molecular Biology Server. A searchable database of protein sequences and their families leading to bibliographic citations, and 3-D color images from the University of Geneva. Access: http://expasy.hcuge.ch/.

- Gaussian Basis Set Library. A searchable database from the Environmental Molecular Sciences Laboratory (EMSL) in Richland, Washington. Access: http://www.emsl.pnl. gov: $2080 /$

- Chemical Information Sources from Indiana University: CIS-IU A Guide to the Main Internet and Other Information Sources for Chemistry. Another excellent, extensive compilation of sources for chemical information. This one is searchable by both natural language and controlled vocabulary. Gary Wiggins, chemistry librarian at Indiana University, has dedicated a lot of time to devising a useful classified arrangement of the most significant chemical information resources on the Internet. He also wants to make users aware of non-Internet resources that may be useful, such as guides to using classic references like Beilstein, Gmelin, and Chemical Abstracts. There are instructional materials for teachers, access to chemistry courses on the Internet, conferences, listservs, and newsgroups. Access: http://www.indiana.edu/ cheminfo/.

- ChemDex Index. The index arrangement is by type and country. Links to conferences, journals, publishers, societies, and university, government, and commercial sites. There are sections on chemical education and software archives by specialty area maintained by Mark Winter, a chemist at the University of Sheffield. Access: http:/www.shef.ac.uk/ $\sim$ chem/chemdex/

\section{Reference fools and data collections}

These would be nice to have bookmarked for easy access to factual information.

- Chemfinder. This is a searchable database with access by common or trivial chemical name, molecular weight or for- mula, or CAS registry number. It even searches for structures drawn in ChemDraw, a chemical software program. For those who may not have ChemDraw but can download ChemDrawNet from the Web, directions are given for a modified structure search. Retrievable information includes melting, boiling and flash point, specific gravity, vapor density, water solubility, RTECS, DOT, and EPA codes. Access: http: chemfinder.camsoft.com.

- WebElements and the Periodical Table. This is one of the many good sources gathered together and managed by Mark Winter, a chemist at the University of Sheffield. Still evolving, WebElements has already won many awards. There are several levels of information about each element. Besicles chemical information, one can click on a menu that leads to physical, nuclear, electronic, biological, geological, crystallographic, reduction potentials, isotope abundances, electronic configurations, and ionization enthalpies data for each element. In some cases, literature sources are given for further reading and verification. Access: http: www.shef.ac.uk/ chem/web-elements/

- The HPLC Troubleshooter. An interesting system devised to give help on what to check if the anticipated results did not occur in spectrographic readings. Access: http: helium.fct.unl.pt/QOF/hplcts1.html.

- Materials Safety Data Sheets (MSDS). An alphabetical list of chemicals giving safety and toxicity information. Access: gopher: atlas.chem.utah.edu:70/11/MSDS.

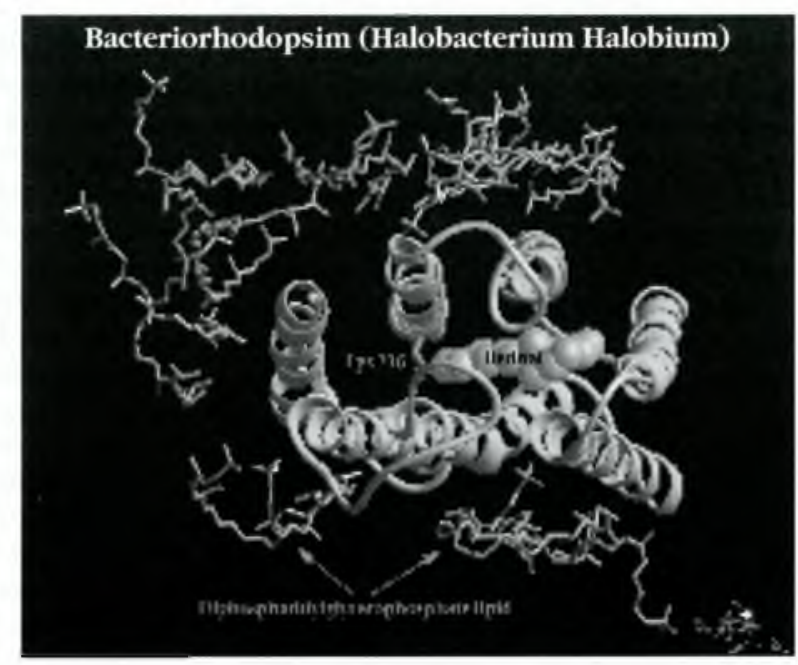

This is part of the Expasy Molecular Biology Server Swiss 3-D Image database at the University of Geneva. 
- Molecular Weight Calculator. Enter the molecular formula for molecular weight information. Access: http://www.chemie.fuberlin.de/cgi-bin/molform.

- Using CAS Databases on STN. A student manual containing eight lessons on developing a search strategy for searching Chemical Abstracts online. This is a tutorial with practice problems on ways to increase or decrease answer sets. Access: http://www.cas.org/ $\mathrm{ACAD} /$ cover.html.

\section{Environmental chemistry and toxicology}

- ECDIN (Environmental Chemicals Data and Information Network). Searchable by EDCIN number, CAS registry number, chemical names, and molecular formula, the Environmental Chemicals Data and Information Net work is a factual databook created by the Joint Research Centre (JRC) of the Commission of European Communities. Its purpose is to make information on chemical products used in the environment accessible to environmental managers and researchers in various fields and disciplines. ECDIN deals with the whole spectrum of facts and properties that might help the user evaluate the real or potential risk in the use of a chemical and its economic and ecological impact. Access: http://ulisse.ei.jrc.it/Ecdin/ Ecdin.html.

- EXTOXNET. The EXtension TOXicology NETwork is a searchable information database on pesticides written for the nonexpert. It is a cooperative effort sponsored by the University of California-Davis, Oregon State University, Michigan State University, and Cornell University. The citations retrieved are mainly from their institutional fact sheets and newsletters which link to full-text articles. Access: http:// ace.orst.edu/info/extoxnet/. Users without a Web browser may telnet to: ace.orst.org and type "lynx" at the login prompt. Press "return" at the password prompt and type "G". Then enter the URL given above.

- EPA Toxic Substances List. Gives hazards summary and workplace exposure limits. Access: gopher://ecosys.drdr.virginia.edu/11/library/gen/toxics.

\section{General listservs and data collections}

- Overview of Chemical Mailing Lists. A comprehensive list of listservs and discussion groups relating to all aspects of chemistry and its specialty areas. There is a good descrip- tion of each site telling whether or not the list is moderated and archived. One helpful feature is that a link is provided to each listserv to subscribe directly. Access: http://bionmr1 rug.ac.be/chemistry/overview.html.

- Internet Chemistry Resources-Databases and Data Collections. Located at Rensselaer Polytechnic Institute, this is a clearly arranged, easy-to-read alphabetical compilation and guide to some of the most important types of specialized databases. Links are organized according to type of server (listserv, FTP, or gopher sites) as well as by type of information (publishers' catalogs, periodicals, conference proceedings, teaching resources, software archives, and data collections). Gives access to most of the government databases. Access: http: /www.rpi.edu/dept/chem/cheminfo/ chemres.html.

\section{Specialized databases}

Here are some more specialized compilations of data and resources that are not listed on the general site given above. One good feature of specialty Web sites is that they have links to the professional societies, conferences, and job opportunities in that field.

- Crystallography Worldwide. A thorough, comprehensive, well-organized collection of all kinds of sites leading to information about crystallography including a worldwide address list of crystallographers, research institutions, journals, and software. Access: http: www. unige.ch/crystal/w3vlc/crystal.index. html.

- MAG-NET-Your Magnetic Resonance Internet Resource Guide. A rapidly growing directory to more than 70 resources worldwide relating to NMR (Nuclear Magnetic Resonance) and MRI (Magnetic Resonance Imaging) which also provides links to gopher and FTP sites, usenet news, electronic mailing lists, conferences, and course, educational, and software information. Access: (current) http://130.101. 9.1:8080/cdept.docs/nmrsites.html. Access: (effective mid-December 1996) http://magnet. chemistry.uakron.edu/

- Organic Chemistry Resources Worldwide. Started this year by chemists for chemists, this is an interestingly arranged, useful collection of all types of information important to organic chemists at the postgraduate level and beyond. It is organized according to task or need and is searchable. Access: http:// 131.96.145.20/post_docs/koen/worgche.htm]. 
- PolyContent Web Site. Links to technical and business information regarding polymers and the plastics industry. A prime example of just how good a Web site can be, the intent is to provide links to content rather than to corporate or advertising sites. Organization is by logical groups and technical level so that it is useful to people in industry and academics. There are introductory-level articles on the various aspects of plastics and polymers, a glossary, a trade name and abbreviations index, and a list of technical reports available on the Web. Access: http://www.polymers.com/dotcom/ polycon/.

\section{Electronic journals-comprehensive listings}

- BetaCyte List of Chemistry Journals. This site bills itself as "the Most Comprehensive Collection of Chemical and BioChemical Journals" on the Web. The journals are organized alphabetically not by subject specialization but by sections that describe how much information is available online (full text or table of contents with or without abstracts) and how free the information is. Access: http://www. betacyte.pair.com/journals. html.

- ESTOC. Elsevier has made the tables of contents to all its journals accessible on the Web by subject area. Contents are searchable by author, title, ISSN, and date. Users can sulsscribe to a TOC e-mail delivery service. Access: http: /www.elsevier.nl/estoc/.

\section{Electronic journals-specialized}

- $L C^{\star} G C$ The Magazine of Separation Science. Provides the tables of contents for articles, columns, and departmental notes in the area of liquid and gas chromatography. Access: http://www.techexpo.com/toc/lcgc.html.

- Theory and Modeling in Chemistry. Only the supplementary material is free but some comes with color pictures. Provides links to related types of journals. Access: http: www.elsevier.nl:80/section/chemical/ theochem/menu.htm.

\section{- Chemistry and Industry Magazine.} Of general interest to a wide audience and international in scope, this site has a synopsis of the articles in its current issue along with document-delivery information. It has today's top stories updated daily and covers news on chemistry and related issues dealing with the commercial and political aspects of new advances in science and technology that affect educa- tion, industry, business, safety, and the environment. There is a Readers' Forum for comments about the articles and a connection to jobs in industry. Access: http://ci.mond.org/.

\section{Patents}

A consideration of chemical information would not be complete without a mention of patents, which are an often overlooked source, and potentially important to many chemists, chemical engineers, and chemical companies. A patent can be granted for a new composition of matter (a drug, catalyst, polymer, or petroleum formulation), a process (synthesis, industrial process, or analytical method), or for a machine or equipment. It is estimated that one-sixth of the patents granted every year are chemical patents and that $10-30 \%$ of these are never published in any other format. The following allow for free searching and limited retrieval.

- QPAT-US. Front page information from all U.S. patents issued since 1974 is available at no charge to those who will register with Questel-Orbit. Paying subscribers can search and retrieve full text. Access: hutp: www.questel.orbit.com/patents/

- U.S. Patents at CNIDR. Covers patents from 1976 to 1996 . Has easy-to-follow instructions for simple two-word Boolean searching and advanced searching techniques. Has a clear explanation of the many searchable fields applicable for patents, gives cited references, references in Chem Abstracts, front page information from the patent, and an abstract. Also has the U.S. Classification Schedule and Class Definitions List. Access: http://patents.cnidr.org/.

\section{Feature your collection on the cover of C\&RL News}

CERL News wants to feature aesthetically pleasing photos of items from library collections on its covers. If you have material in your library's collections that you think would make an attractive CERL Neus cover, please send us a photograph or a color photocopy and a brief description of the item and the collection. Photos may be either color or black-and-white and should be $5^{\prime \prime} \times 7^{\prime \prime}$ or $8^{\prime \prime} \times 10^{\prime \prime}$. Illustrations with a vertical arientation work best. Send to: CERL News Covers, 50 E. Huron St., Chicago, IL 60611 